\title{
A visibilidade política na série The Crown
}

\author{
La visibilidad politica en la serie The Crown \\ Political visibility in 'The Crown'
}

\author{
Giovana dos Passos Colling ${ }^{1}$ \\ Julia Sousa Capelaro
}

\begin{abstract}
Resumo
O presente trabalho tem por objetivo compreender como se configura a visibilidade política na trama da série The Crown, produzida pela Netflix, por meio da análise dos três primeiros episódios. A partir do enredo da série, que conta a história da família real britânica na época em que a Raínha Elizabeth II assume o trono e suas novas responsabilidades políticas, é possível perceber e analisar as relações de poder entre a política, a sociedade e a mídia, além de temáticas como imagem pública, escândalo político, relações políticas entre países e discurso midiático. A análise de conteúdo se dá a partir dos autores Gomes, Thompson e Weber. Assim, torna-se perceptível a indissociabilidade entre a mídia, a sociedade e a política para a manutenção de um governo estável, que se utilizando da visibilidade midiática de maneira favorável, estabelece uma comunicação eficiente e uma imagem pública forte e positiva.
\end{abstract}

Palavras-Chave: Comunicação Política; Relações de poder; The Crown; Visibilidade política.

\section{Resumen}

El presente trabajo tiene por objetivo comprender cómo se configura la visibilidad política en la trama de la serie The Crown, producida por Netflix, por medio del análisis de los tres primeros episodios. A partir de la trama de la serie, que cuenta la historia de de la familia real británica en la época en que la Reina Elizabeth II asume el trono y sus nuevas responsabilidades políticas, es posible percibir y analizar las relaciones de poder entre la política, la sociedad y los media, además de temáticas cómo imagen pública, escándalo político, relaciones políticas entre países y discurso mediático. El análisis de contenido se da a partir de los autores Gomes, Thompson y Weber. Así, se hace perceptible la indisociación entre los media, la sociedad y la política para el mantenimiento de un gobierno estable, que utilizando la visibilidad mediática de manera favorable, establece una comunicación eficiente y una imagen pública fuerte y positiva.

Palabras claves: Comunicación política, Relaciones de poder, The Crown, Visibilidad política.

\begin{abstract}
The objective of this work is to understand how the political visibility in the plot of The Crown, produced by Netflix, is configured through the analysis of the first three episodes. From the plot of the series, which tells the story of the British royal family at the time Queen Elizabeth II takes the throne and her new political responsibilities, it is possible to perceive and analyze the power relations between politics, society and the media as well as themes such as public image, political scandal, political relations between countries and media discourse. The content analysis is based on the authors Gomes, Thompson and Weber. Thus, the indissociability between the media, society and politics for the maintenance of a stable government, which uses media visibility in a favorable way, establishes efficient communication and a strong and positive public image.
\end{abstract}

\footnotetext{
${ }^{1}$ Estudante de graduação de Comunicação Social - Publicidade e Propaganda; Faculdade de Biblioteconomia e Comunicação - Universidade Federal do Rio Grande do Sul; Porto Alegre, Rio Grande do Sul, Brasil; giovanacolling@gmail.com

${ }^{2}$ Estudante de graduação de Comunicação Social - Publicidade e Propaganda; Faculdade de Biblioteconomia e Comunicação - Universidade Federal do Rio Grande do Sul; Porto Alegre, Rio Grande do Sul, Brasil; julia_capelaro@hotmail.com
} 
Keywords: Political Communication; Power relations; The Crown; Political visibility.

\section{Introdução}

Segundo Gomes (2004), a preocupação com a imagem pública se tornou parte inseparável da política contemporânea e entende-se por imagem pública àquela que o público tem de alguém ou alguma coisa. Essa preocupação é fundamental para o exercício político, pois ele é feito para a sociedade, e uma imagem boa passa confiança e gera maior legitimidade.

O escândalo político é um fenômeno que acontece predominantemente no espaço público e está relacionado com o caráter de mudança dos meios de comunicação, que transformaram a natureza da visibilidade e alteraram as relações entre a vida pública e privada (THOMPSON, 2002). Para o autor, quando se perde o controle sobre a imagem pública por meio de ações de transgressão à moral social, que gera resposta do público, tem-se o escândalo político. Este é uma ameaça constante aos atores políticos que têm suas vidas constantemente expostas pela mídia.

Além da exposição destes atores, a mídia também tem o poder de difusão dos demais poderes. Isso se dá, pois o seu é suportado pela capacidade de disseminação política, que gera maior visibilidade, e por consequência vulnerabilidade ao Estado (WEBER, 2000). Entretanto, esta vulnerabilidade é o que favorece a construção de uma boa imagem pública e, consequentemente, contribui para a manutenção do poder.

Esses assuntos podem ser percebidos na série The Crown, produzida pela Netflix. Segundo a empresa de entretenimento, a série “[...] segue a política, rivalidades e relacionamentos da rainha Elizabeth II, e os eventos que fizeram a história." (NETFLIX, 2016). A partir da relação entre política, mídia e sociedade, o presente trabalho tem como objetivo buscar, através do objeto escolhido, analisar de que forma se configura a visibilidade política acerca dos atores políticos e os impactos da mesma em suas vidas, principalmente, por conta da série ser inspirada em acontecimentos reais. Dessa forma, esta análise de conteúdo da trama possibilita a reflexão a respeito da visibilidade e imagem pública, além de pensar as relações entre a tríade: política, mídia e sociedade.

\section{The Crown e o Reino Unido}

A série The Crown, da Netflix, foi criada por Peter Morgan e lançada em novembro de 2016. Baseada em fatos reais, ela conta a trajetória de Elizabeth Mountbatten para Elizabeth II e suas novas obrigações e responsabilidades como rainha do Reino Unido. A nova rainha 
precisa construir sua imagem de soberana, administrá-la e mantê-la forte, para que ela possa passar confiança à população e demonstrar que manterá o legado de grandes feitos das demais rainhas que a antecederam.

O Reino Unido é composto pela Inglaterra, Escócia, País de Gales e Irlanda do Norte. Ele possui um sistema político de monarquia parlamentarista, no qual a Rainha Elizabeth II é a chefe de Estado, porém o Poder Legislativo é investido no Parlamento, e o Executivo no Gabinete, comandado pelo Primeiro-Ministro. Segundo Thompson (1998, p. 52), “[...] o estado inglês se erigiu numa forma de constitucionalismo no qual o poder do monarca foi moderado por uma grande ênfase no governo da lei, na separação dos poderes e no papel da oposição - tanto dentro quanto fora do Parlamento". Apesar de ser monarca, Elizabeth II exerce apenas funções não partidárias simbólicas, como eventos oficiais, cerimônias, convocações e nomeações de Primeiro Ministro, entre outras. "Como chefe de Estado, a rainha Elizabeth é um símbolo vivo para várias nações” (MARR, 2012, p. 25), então, apesar da monarquia não exercer nenhuma função executiva ou legislativa, ela detém poder, pois, como demonstrado em diversos momentos da trama, a monarca precisa lidar com e resolver situações complicadas, e, segundo Marinho e Nunes (2017, p. 3), “[...] o poder é uma forma de resolver conflitos, tanto no âmbito da macro quanto da micropolítica". A partir disso, é possível analisar a visibilidade dos atores políticos considerando o poder das mídias de massa, sendo elas principalmente o rádio, o jornal e a televisão no período em questão; da sociedade e as relações de poder que envolvem todos os personagens, tanto os do núcleo pessoal e familiar de Elizabeth, quanto da população e dos políticos, como o primeiro-ministro e os parlamentares.

A primeira temporada se passa durante o final dos anos 1940 e na década 1950. O contexto que embasa a trama é de Guerra Fria, pós Segunda Guerra Mundial. Neste período, também, o Reino Unido está perdendo sua influência em territórios na África e Ásia. O livro A Mídia e a Modernidade de Thompson (1998), ressalta a importância das colônias dos séculos XV a XVIII :

Enquanto os estados europeus foram consolidando seu controle sobre territórios limítrofes na Europa Continental, algumas potências européias foram expandindo seus círculos de influência ultramar. Os territórios estrangeiros forneceram fontes adicionais de renda para os estados europeus e se tornaram importantes parceiros comerciais para as firmas capitalistas e comerciais sediados na Europa. Com o crescimento da importantância econômica dos territórios ultramarinos, as maiores potências européias dedicaram a maior parte de seus recursos para manter e expandir suas esferas de influência e para se prevenirem das ameaças de rivais. (THOMPSON, 1998, p. 51). 
Em The Crown, a dedicação para manter a influência nesses territórios, mesmo após a independência deles, é mostrada no momento em que o Rei George VI pede à Elizabeth e seu marido, Philip, para irem na turnê da Commonwealth em seu lugar. Este e outros momentos da vida política podem ser percebidos na série e, por este motivo, a partir da base teórica serão aqui analisados, principalmente, no que se refere aos aspectos comunicativos.

\section{Comunicação política em The Crown}

Na série se percebe a importância de uma boa administração da imagem pública. A imagem da família real era construída para que a opinião pública sobre os mesmos fosse positiva. Afinal, como afirma Weber (2000, p. 11) a política se constrói para a sociedade, “[...] seu modo de falar tem a lógica da retórica, do convencimento da comprovação, da busca de confiança, aprovação ou obediência”. O Rei George VI, então, quando doente, não quis aparentar seu estado, pois, isto significaria demonstrar uma fraqueza do soberano e, consequentemente, isto diminuiria a confiança da população nele e, possivelmente, seu poder. Para não 'enfraquecer' sua imagem pública e também para não perder seu poder em relação ao Primeiro Ministro chegou a se maquiar e, ao sair em público, tentava parecer animado.

Após seu falecimento, sua filha Elizabeth se torna a rainha e, toda esta preocupação com a imagem pública recai sobre a mesma. Segundo Gomes (2004, p. 278), “A primeira função da política de imagem é justamente a criação, produção, construção da imagem pública de atores, classes de atores e instituições políticas”. Assim, Elizabeth II precisa construir sua imagem de soberana. Ela deve se manter forte, para sustentar a situação, ser cortês, seguir a padrões preestabelecidos de comportamento, como por exemplo, se mudar para a casa principal, dedicar-se a eventos públicos, manter o sobrenome de sua família, se impor frente ao Primeiro Ministro, entre outros. Esse posicionamento é, também, indicado por sua avó, mãe do Rei George VI, desde o momento em que Elizabeth retorna ao Reino Unido após a morte de seu pai. O conselho dado pela avó é de que a antiga Elizabeth também já não existe mais, a prioridade deve sempre ser a coroa, a imagem pública da mesma (Figura 1). 


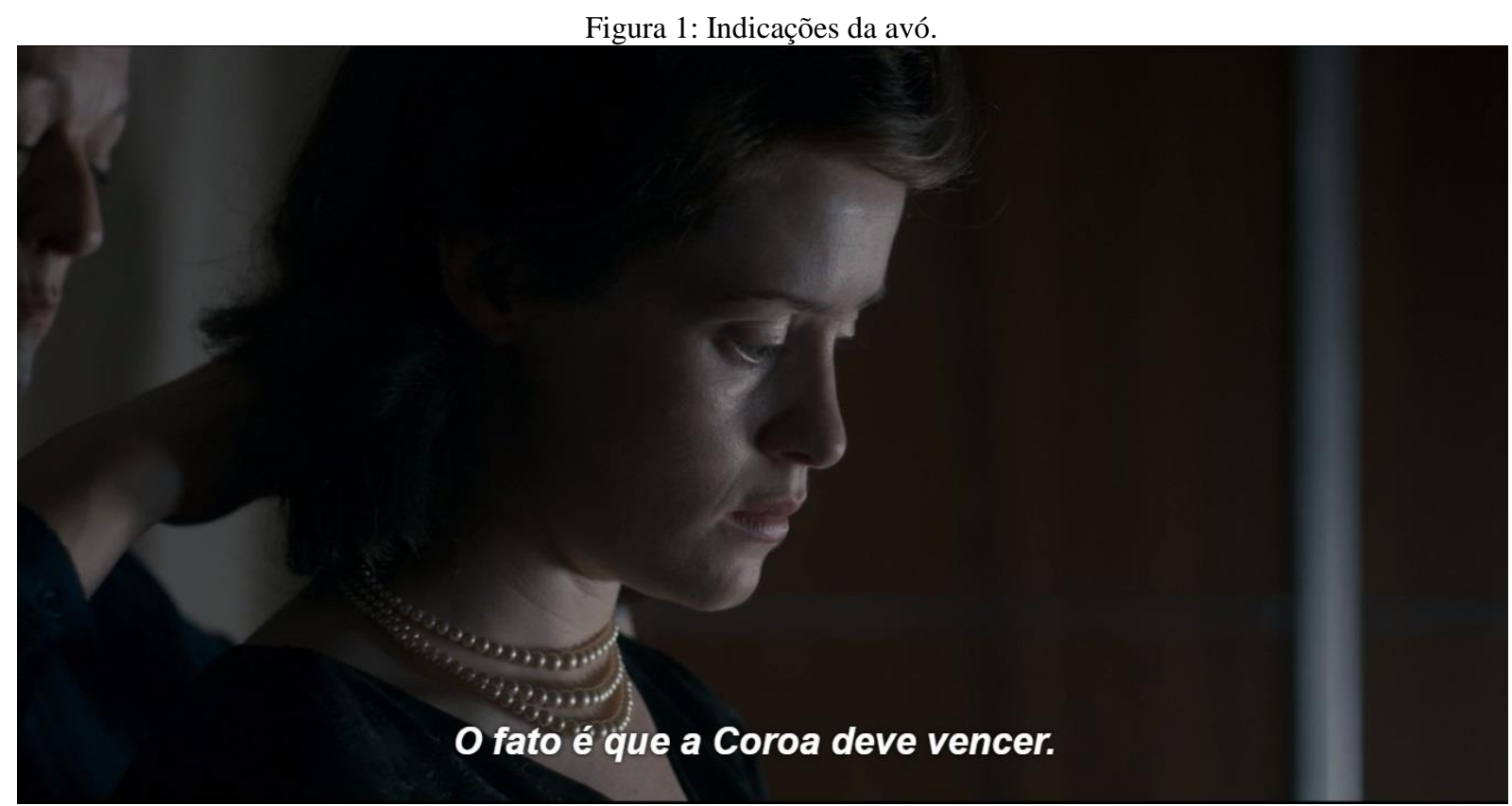

Fonte: The Crown, 2016.

Isso causa adversidades em sua vida pessoal, mas a imagem pública acaba sendo mais importante em um primeiro momento. Um exemplo disso é a cena no terceiro capítulo da série em que Elizabeth diz ao marido que vai manter o sobrenome da família ao invés de adotar o sobrenome dele, e que eles terão de se mudar para o palácio de Buckingham pois é o mais aconselhável pelo parlamento. Ele questiona: "Mas essa é a questão. É só um conselho. Não significa que precisa segui-lo", e ela rebate: "Quando vem do governo, precisa". Pois, através dessas ações, que funcionam como estratégias de comunicação, ela afirma seu o poder político que, segundo Weber (2000), precisa se legitimar e se promover.

A pressão para que Elizabeth seja uma soberana respeitada vem também por conta da imagem consolidada de seu pai como um bom rei, como afirma Winston Churchill no terceiro capítulo: "Sua Majestade foi um herói para mim e para toda a sua gente". Ainda no mesmo episódio, ele reforça o que disse em um discurso anterior: "Grandes coisas aconteceram a este país sob o cetro de rainhas e a senhora não deve ser exceção", o que põe mais tensões sobre a nova soberana, que deve construir sua imagem pública com base em personalidades que tiveram um bom reconhecimento pela sociedade, o que consequentemente, facilitou o exercício do poder.

A questão da política de imagem também pode ser vista acerca de Winston Churchill na série. No primeiro episódio, Churchill é propositalmente o último a chegar ao casamento de Elizabeth e Philip e ao entrar na igreja é recebido de pé pelos convidados. Na época ele era ex-Primeiro-Ministro e estava concorrendo novamente ao cargo, dessa forma, estava se 
utilizando de recursos para manter sua boa imagem pública e garantir vitória na eleição, como, por exemplo, fazer uma entrada memorável em um evento importante. Quando vence a eleição, alguns integrantes de seu partido querem afastá-lo por acharem que ele está velho demais para o cargo, o que faz com que Churchill encontre obstáculos na batalha pelo controle da imagem pública. Para Gomes (2004), isso se trata “[...] não apenas de produzir a sua imagem como também fazer com que o adversário perca o controle da própria imagem” (GOMES, 2004, p. 286). Um exemplo disso, tem-se após a morte do rei George VI, no segundo episódio, quando Churchill está preparando o discurso de homenagem que vai fazer no rádio e sua esposa lhe diz: "Vão querer que você falhe". E ele responde: "Eu sei. Qualquer coisa menos do que perfeita será um desastre". Dessa forma, vimos que os adversários de Churchill estavam o pressionando e esperando que ele perdesse o controle sobre sua imagem pública e falhasse, gerando uma desculpa para afastá-lo do cargo. Para se evitar esses descontroles quanto à imagem pública, os atores políticos utilizam táticas de administração de imagem de modo a prever as formas de decodificação e recodificação dos fatos por meio da mídia e decodificação da informação pela sociedade.

Em The Crown, também é possível perceber a temática do escândalo político. $\mathrm{O}$ escândalo é um fenômeno que acontece predominantemente no espaço público e está relacionado com o caráter de mudança dos meios de comunicação, que transformaram a natureza da visibilidade e alteraram as relações entre a vida pública e privada (THOMPSON, 2002). O tema é percebido acerca dos personagens Rei Edward VIII e da irmã de Elizabeth, Margareth e seu caso com Peter Townsend.

Edward VIII, quando ainda rei, decidiu se casar com uma mulher divorciada, porém, o Parlamento não aprovou pois, seria negativo para a imagem do reinado e, também, porque o povo não aceitaria uma divorciada como rainha. Assim, ele decidiu abdicar ao trono com menos de um ano de reinado para poder ficar se casar, passando o título ao seu irmão, rei George VI. Após essa decisão, houve muita polêmica a respeito do assunto e a família se posicionou contrária à situação de Edward. No terceiro episódio da série, ele está prestes a fazer um discurso sobre o acontecimento e sua mãe o aconselha a não dizer nada, a sair discretamente mas, ele contesta dizendo: "os jornais me procuraram". Ainda depois desse escândalo e de ter deixado o país, Edward é recebido com certo carinho pelo povo e pela imprensa ao retornar à Inglaterra para o enterro de seu irmão, pois percebe-se o interesse em ouvir seus discursos e de recebê-lo no porto com aplausos e saudações. Conforme Gomes (2004), 
Enquanto tiver capacidade geradora de fatos e de discursos (mesmo que seja apenas o 'falem mal mas falem de mim') o ator político continuará emitindo as mensagens que, depois de recodificadas na indústria da informação, serão recebidos como insumos na produção de imagem pelo público (GOMES, 2004, p. 282).

Dessa forma, percebe-se que apesar da situação ocorrida, ele soube administrar sua imagem pública e lidar com o escândalo de forma a continuar mantendo, de certo modo, uma imagem positiva para, pelo menos, uma parte da população.

No caso de Margareth, irmã mais nova de Elizabeth, a situação não se tornou um escândalo até o terceiro episódio, mas, tem grandes possibilidades de que se torne um, pois, segundo Thompson (2002), “[...] nessa era moderna de visibilidade mediática, o escândalo é um risco que ameaça constantemente tragar os indivíduos cujas vidas se tornaram o foco da atenção pública" (THOMPSON, 2002, p. 31). Margareth mantém um caso secreto com Peter Townsend, um funcionário real e ex-oficial das forças armadas, um homem casado, com filhos e mais velho do que ela. No primeiro capítulo da série, quando Elizabeth contesta os olhares que viu sua irmã trocar com Peter, Margareth responde: “Os jornais pensam que gosto de Johnny Dalkeith ou Billy Wallace”. Isso demonstra a preocupação com a importância que a mídia dá aos relacionamentos pessoais das figuras públicas e a oportunidade que a personagem tem para utilizar isso a seu favor, tentando evitar com que haja especulações sobre seu caso secreto.

Ambas as situações demonstram um ato de quebra de valores morais, segredo ou ocultamento do acontecimento, desaprovações de não-participantes e revelação do ato, características presentes na definição de escândalo de Thompson (2002, p. 40): “[...] escândalo se refere a ações ou acontecimentos que implicam certos tipos de transgressões que se tornam conhecidos de outros e que são suficientemente sérios para provocar uma resposta pública".

Ao fim do primeiro episódio, quando o Rei , por causa de seu estado de saúde, está debilitado, ele pede que Elizabeth faça a Turnê de Commonwealth em seu lugar, onde viajará por meses visitando colônias como Ceilão, Austrália, Nova Zelândia, Bermudas, Nairóbi e Quênia. É esta viagem que acompanhamos durante o início do segundo episódio, quando a Princesa está na África conhecendo o continente e estreitando relações com os governantes locais. Toda sua viagem é acompanhada por diversos repórteres, que tem como intenção cobrir as visitas da Princesa e seu marido, que são transmitidas no rádio e na televisão para que a população possa acompanhar - em uma cena do episódio é possível ver o Rei George VI acompanhando os relatos da viagem de sua filha. 
Em muitos momentos se vê a presença da mídia na série, que inicia no ano de 1947 (Figura 2). Valorizou-se muito mais as mídias e seu poder estético, principalmente o rádio e a televisão, que facilitam o comércio de notícias e, assim, a 'validação' dos acontecimentos. Esse poder da mídia também é utilizado pelo poder político, como para se evitar descontroles quanto à imagem pública, por meio de táticas de administração de imagem, de modo a prever as formas de decodificação e recodificação dos fatos por meio da mídia e decodificação da informação pela sociedade, que recebe os acontecimentos a partir da mídia.

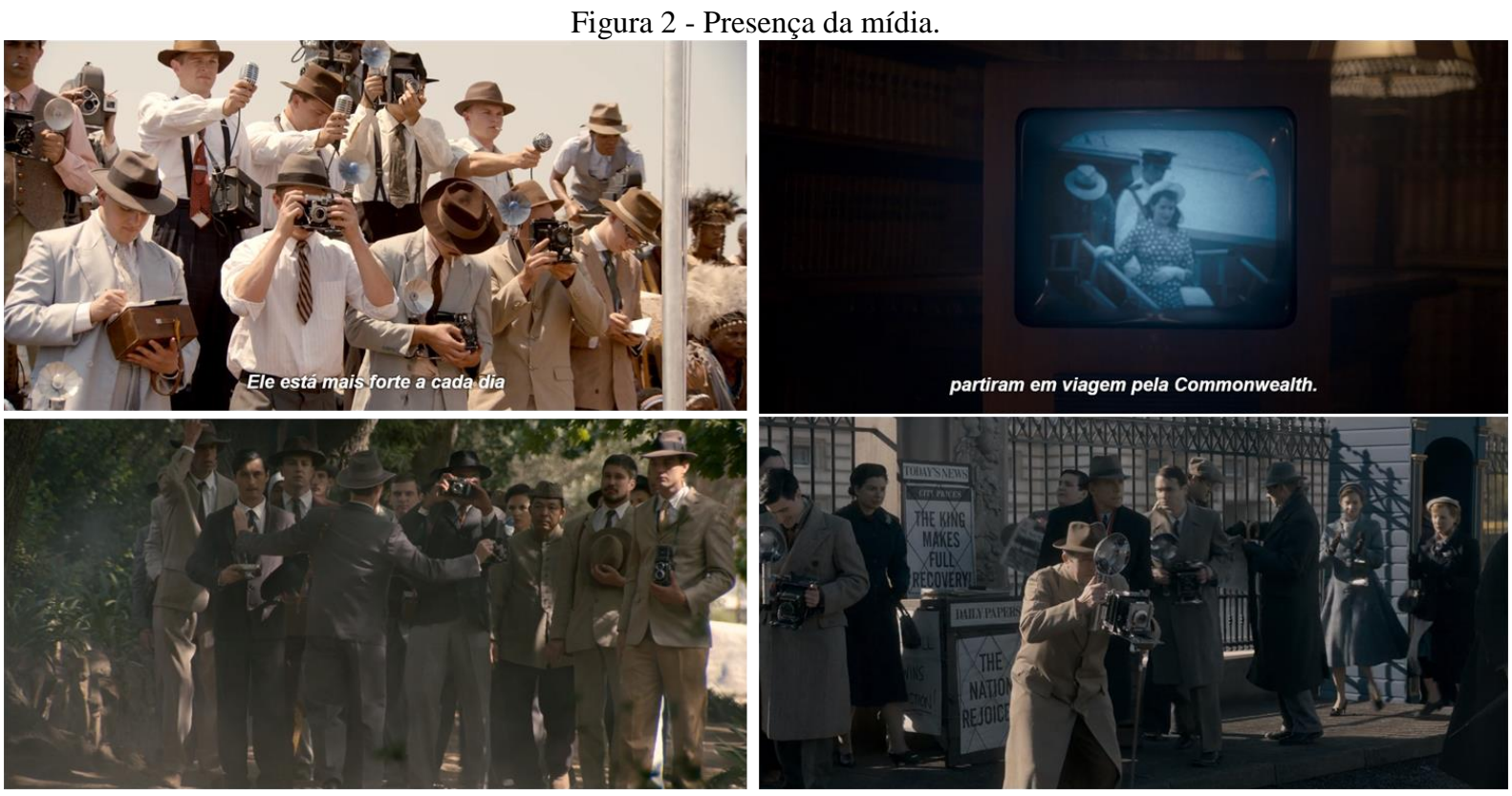

Fonte: The Crown (composição nossa), 2017.

Em The Crown, a mídia cobre os principais acontecimentos, utilizando-se do seu poder de difusão de outros poderes, como afirma Weber (2000), desde o casamento de Elizabeth até sua ascensão ao trono. O acontecimento que gerou mais desdobramentos foi a morte do rei George VI. Logo após o falecimento, o primeiro ministro Churchill ficou responsável por liberar a veiculação da notícia. Ele tenta avisar Elisabeth, que está viajando, do ocorrido antes, sem sucesso, e, por pressão da imprensa libera a notícia para divulgação. Após a veiculação, o 'assessor' de Elizabeth se apressa para avisá-la pois, o acontecimento já está sendo difundido em diversos países, na televisão e no rádio. Além disso, já há muitos repórteres em frente à residência onde ela e o marido estão. Churchill também se utiliza da mídia para proferir seu discurso sobre o falecimento e, aqui, “[...] o poder das mídias reside, essencialmente, na sua capacidade de irradiação política que torna o Estado mais visível, mais vulnerável às negociações necessárias para a obtenção desta visibilidade” (WEBER, 2000, p. 17), por estar vulnerável, este discurso é decisivo para a manutenção do poder. 


\section{Considerações Finais}

Na série The Crown, da Netflix, pode-se perceber, então, muitos aspectos relacionados à comunicação política, desde imagem pública, escândalos, relações midiáticas, entre outros, que permitem analisar como se dá a visibilidade política na série. Percebe-se como a mídia, a sociedade e a política estão fortemente ligadas, pois para se manter um governo estável, é preciso uma comunicação sólida, uma imagem positiva e uma visibilidade favorável. A construção e manutenção de uma imagem pública forte é essencial para manter, também, uma ligação forte com o público que decodifica as informações passadas por meio da mídia. Todo esse esforço é percebido nos três episódios analisados por parte de todos os atores políticos envolvidos na trama.

Os atores e instituições políticas prezam por passar um quadro positivo das situações aos receptores, utilizando de táticas de administração de imagem para prever as formas de decodificação e recodificação por meio da mídia e decodificação da informação pela sociedade, mas nem sempre isso tem sucesso. Assim, às vezes a imagem passada é distorcida da imagem desejada, e, muitas vezes, isso pode ocasionar problemas como o vazamento de informações que podem gerar escândalos e crises políticas.

Weber (2000) afirma que “A política, como as mídias, detém o poder das palavras. Essas carregam a legitimidade de quem as pronuncia e, se adotadas adequadamente, como táticas, produzem efeitos reais" (WEBER, 2000, p. 13). Na série isto é perceptível, as mídias influenciam diretamente na política e na sua difusão para a sociedade. O poder político percebe o potencial da mídia e, através de estratégias, consegue formular sua publicização, para provocar determinados impactos nos receptores e gerar determinadas repercussões na sociedade.

Partindo-se disso, a relevância do presente trabalho reside na atualidade do tema, que é percebido cotidianamente, principalmente em um momento de crise política. Os conceitos aplicados e analisados na obra audiovisual The Crown podem, então, ser úteis para o entendimento das relações de poder no momento presente visto que a mídia, a sociedade e a política são, como percebido neste estudo, indissociáveis.

\section{Referências}

GOMES, Wilson. A política de imagem. In: As transformações da política na era da comunicação de massa. São Paulo: Paulus, 2004. 
MARINHO, William Ricardo Vidal; NUNES, Ana Karin. A Monarquia é ela: a função política de Relações Públicas em uma forma de governo. In: XVIII Congresso de Ciências da Comunicação na Região Sul - Caxias do Sul - RS - 15 a 17/06/2017.

MARR, Andrew. A real Elizabeth: uma visão inteligente e intimista de uma monarca em pleno século 21. São Paulo, SP: Editora Europa, 2012.

THE CROWN. Produção: Netflix. 2016.

THOMPSON, John Brookshire. A Mídia e a Modernidade: Uma Teoria Social da Mídia. Petrópolis, RJ: Vozes, 1998.

THOMPSON, John Brookshire. O Escândalo Político: Poder e Visibilidade na Era da Mídia. Petrópolis, RJ: Vozes, 2002.

WEBER, Maria Helena. Comunicação e espetáculos da política. Porto Alegre: Ed Universidade/UFRGS, 2000. 